\title{
EVOLUÇ̃̃o CLÍNICA de UM PACIENTE SEPTICÉMICO - A INTEŔRFRÊNCIA DA EQUIPE DE SAÚDE E DA FAMÍLIA NO ASPECTO EMOCIONAL DO PACIENTE
}

\author{
Autora : Maria dos Reis Pereira da Silva* \\ Co-autores : Lacy Machado Braga** \\ : José Ribamar Araújo ***
}

ReBEn/03

SILVA, M.R.P. e Colaboradores - Evolução clínica de um paciente septicêmico. A interferência da equipe de saúde e da família no aspecto emocional do paciente. Rev. Bras. Enf.: DF, 33 : 418-423, 1980.

\section{INTRODUÇÃO}

Num itinerário desde os tempos escolares de universidade aos dias de profissional, numa e noutra situação ao lado do paciente na execução e na liderança do cuidado de Enfermagem, toda(o) enfermeira(o) vive cotidianamente as mais variadas experiências que envolvem o ser humano na sua totalidade. Nessas experiências há que se salientar os aspectos psicológicos do paciente nas suas exigências de satisfação emocional de atenção, carinho, respeito à sua pessoa como cidadão capaz de direitos e obrigações, ainda que temporariamente impedido do seu pleno exercício.

A partir de tais observações e cons- cientes do importante papel que exercemos nesse contexto do paciente hospitalizado, tendo em mente, sobretudo, os seus valores na esfera da personalidade e também porque, desempenhan. do há vários anos atividades em Clínica Médica, onde se torna possível um maior relacionamento diário e uma percepção mais real dessas necessidades, é que resolvemos fazer das obser . vações rotineiras dos comportamentos de pacientes uma análise mais profunda e seguir avaliando as reações e os resultados do comportamento $\overline{\mathrm{d} a}$ equipe de Enfermagem frente às necessidades afetivas que interferem ou retardam o processo de cura do paciente.

* Enfermeira-Chefe da Clínica Médica da Unidade Integrada de Saúde de Sobradinho e do Posto do INAMPS de Planaltina - DF.

** Enfermeira-Chefe da UTI da Unidade Integrada de Saúde de Sobradinho e do Centro Cirúrgico e Obstétrico do Hospital Regional de Planaltina.

*:*: Médico Residente do Serviço de Anatomia Patológica da Faculdade de Medicina da Universidade de Brasília e do Instituto de Medicina Tropical de Manaus. 
SILVA, M.R.P. e Colaboradores - Evolução clínica de um paciente septicêmico. A interferência da equipe de saúde e da família no aspecto emocional do paciente. Rer. Bras. Enf.: DF, 33 : 418-423, 1980.

Assim, as situações enfrentadas pela equipe de Enfermagem que trabalha em Clínica Médica leva o grupo a reagir de forma surpreendente.

A enfermeira ao lado de seu paciente sente-se muitas vezes, mesmo que não queira, envolvida emocionalmente, manifestação esta que varia de pessoa para pessoa, levando-a a proceder de maneira não coerente em determinadas situações que infringem um esquema arraigado de rotinas hospitalares, implantado através de longos anos de vivência, transmitido de uma equipe de Saúde anterior à que lhe sucede.

Classicamente, aceita-se que o paciente em regime de isolamento terá que permanecer dessa forma para evitar propagação de sua doença. No entanto, pela observação mais analítica, baseada nos ensinamentos da moderna psicologia, verifica-se que:

01 - O isolamento físico pode ser problemático num paciente que ainda não amadureceu na sua vida de relacionamento.

02 - A carência afetiva influindo no psiquismo do paciente poderá retardar a sua recuperação somática.

A experiência por nós vivida, e que ora relatamos, enche-nos de emoção, viva e contagiante, que, pouco a pouco, a todos envolve e domina, quebrando os rígidos ensinamentos por nós absorvidos, anteriormente.

\section{REVISÃO DA LITERATURA}

Favretto, 1977, em seu lívro "O doente: Razão de ser do Hospital", chama a atenção de toda a equipe de Saúde para $o$ aspecto fundamental da influência do momento da internação do paciente que o leva a um estado de "trauma psíquico que influi negativamente sobre seu estado de alma e sobre a evolução de sua enfermidade".
Cita como causas desse trauma a maneira impessoal e desumana em que, muitas vezes, ocorre essa admissão. Salienta ainda o fato da separação do paciente por guichês de vidro, dos funcionários que fazem o seu registro nesse momento. Continua enfatizando esse sistema de separação na própria enfermaria onde é internado o paciente, fazendo suas referências com relação aos pontos de informação, aos sistemas de sinalização, às salas de espera, que muitas vezes não proporcionam o contato necessário da equipe de Saúde com o paciente. Continua o autor, referindo-se como causa de grande ansiedade, a percepção, pelo paciente, da perda do bem inestimável, a saúde, dando-lhe a sensação de invalidez. Em tudo isso ele percebe a perda de sua individualidade, quando os aspectos humanos são totalmente sufocados pelos aspectos técnicos e as rotinas hospitalares, utilizados pelo pessoal de Saúde.

Mason, 1976, tece diversas considerações em "Enfermagem Médico-Cirúrgica", sobre o fator ansiedade quando desenvolve o capítulo do "Impacto da Enfermidade sobre o indivíduo", ao tratar das alterações de comportamento e dos métodos comuns de ajustamento utilizados pelo paciente. Em suas considerações, ele salienta o mecanismo da ansiedade, provocada por um desconforto em resposta a algum temor ou perigo desconhecido. Mostra também a conseqüência da situação de ansiedade, que leva o indivíduo à reação de defesa que se exterioriza por alterações emocionais, como chorar, tornar-se zangado, como também por alterações somáticas, pelo débito aumentado de adre. nalina, ocasionando, muitas vezes, alterações na freqüência do pulso e da respiração, da pressão arterial, etc...

Tudo isto, podendo ocasionar outros distúrbios, como insônia, perda do apetite, dores abdominais, vômitos, diarréia, etc. 
SILVA, M.R.P. e Colaboradores - Evolução clinica de um paciente septicêmico. A interferência da equipe de saúde e da família no aspecto emocional do paciente. Rev. Bras. Enf.: DF, 33 : 418-423, 1980.

O autor chama atenção para o fato de que esse processo de ansiedade é, às vezes, desencadeado por certos procedimentos diagnósticos e terapêuticos que podem ser percebidos pelo paciente, como ameaçadores de sua segurança.

\section{RELATO DO CASO}

A observação do presente caso desenvolve-se a partir das considerações até aqui tratadas. A pessoa por nós cuidada, tratava-se de paciente do sexo masculino, 13 anos, registro n. ${ }^{\circ} 192.900$, estudante e engraxate, católico, cursando a $3 .^{a}$ série do primeiro grau, admitido em 13-11-1979 no Pronto Socorro da UISS. Apresentava naquele momento os seguintes sintomas: febre, manchas no corpo e queixa de dor na perna esquerda. Informava que a enfermidade se manifestara a cerca de cinco dias, com quadro de cefalalgia intensa e difusa e edema na articulação do tornozelo. No Pronto Socorro, o quadro foi diagnosticado como de septicemia, sendo, por isso, encaminhado à enfermaria de isolamento da Clínica Médica da Unidade.

No primeiro dia de internação, a conduta clínica, embora já com essa hipótese diagnóstica grave, foi apenas expectante, o que nos deixou em situação apenas de observação, não obstante nossa angústia pela percepção da gravidade do caso. O menor em pauta apresentava facies de sofrimento, sudorese facial, extremidades frias, gemente, abdômen tenso e rígido, com placas avermelhadas, MMII sensiveis a pequenos toques e mialgia generalizada. Durante a evolução do seu estado patológico apresentou auto-halo-psíquico, PA inaudível, temperatura $39^{\circ} \mathrm{C}$, apresentando quadro de choque séptico.

Nesse ínterim foi levantada a hipótese diagnóstica de abdômen agudo pela equipe cirúrgica, sendo afastada em seguida tal suspeita. Agravou-se o quadro clínico com o surgimento de abces- sos nas regiōes deltodiana $\mathrm{D}$ e calcânea E, distúrbio da coagulação sangüínea, endocardite bacteriana, precordialgia e hepatoesplenomegalia, conforme constatações clínicas.

Os abcessos que apareceram foram drenados, evoluindo satisfatoriamente 0 quadro clínico, com o paciente podendo levantar-se do leito, sentar-se, porém, sem condições de deambular. No $30 .^{\circ}$ dia foi diagnosticada osteomielite crônica, aparecendo a seguir reação alérgica à medicação, quadro febril e o quadro de hepatoesplenomegalia manteve-se até a regressão total dos demais sintomas. No 36.0 dia fez-se debridamento de calcâneo, com magnífica recuperação, e o paciente recebeu alta da Clínica Médica no dia 11-1-1980, permanecendo até o momento em acompanhamento pela Clínica Ortopédica.

Ressalvamos aqui o papel fundamental da equipe de Saúde numa clínica Geral, com enfermaria de isolamento, em que, apesar das situações críticas da doença, o trabalho realizado pela equipe evitou a propagação da moléstia em outros pacientes ali internados. Pudemos então inferir que, em determinadas circunstâncias, às vezes sem perceber, toda uma equipe deixa envolver-se técnica e emocionalmente por um paciente e sua patologia, chegando mesmo a sofrer com ele. Talvez este envolvimento tenha-se despertado inconscientemente a partir da equipe de enfermagem, devido aos três fatores importantes, demonstrados durante a permanência do paciente no hospital: fé inquebrantável, associada à vontade de viver, responsabilidade e dedicação da família e a gravidade do caso.

\section{DISCUSSÃO}

A "abordagem" do paciente pela equipe de Saúde, na ânsia de um rápido diagnóstico e a necessidade urgen- 
SILVA, M.R.P. e Colaboradores - Evolução clínica de um paciente septicêmico. A interferência da equipe de saúde e da família no aspecto emocional do paciente. Rev. Bras. Enf.: DF, 33 : 418-423, 1980.

te da terapêutica, não possibilitou a percepção de que o paciente, embora um adolescente, era também um ser humano, sujeito a todas as necessidades de atenção emocional. A anamnese é sempre dirigida apressada, com perguntas secas e objetivas, em que o paciente fala, mas o adulto é quem diz a verdade; a queixa do paciente não é ouvida ou é relegada a segundo plano, criandose, assim, uma situação de resistência entre equipe de Saúde e paciente.

Ora! pacientes portadores de septicemia continuam chegando todos os dias na enfermaria, todavia, raros são aqueles que nos chamam a atenção, levando a uma identificação paciente e equipe. Lamentavelmente, esses, no dia vão sendo pouco a pouco despersonalizados, passando a ser "o 601", “o diabético", "o cirrótico", "o septicêmico". Todos nós sabemos, mas o erro persiste. O nosso envolvimento teve início com a chegada do paciente na emergência, chamando nossa atenção a cena de angústia e medo da morte, traduzida em expressões como estas:

- Doutor, me salve!...

- Enfermeira, me ajuda!...

- Eu não posso morrer!...

Cotidianamente ao abordar os pacientes, a equipe de Saúde de modo geral, assume o papel de inquisidora, marcando-os profundamente, traumatizando-os, desenvolvendo um quadro de rejeição em muitos desses pacientes. Tal fato pode ser constatado na entrevista que realizamos com o paciente. De acordo com os novos conceitos de socialização do paciente, a família exerce papel fundamental na recuperação dos mesmos, como o caso aqui citado. Recebendo a visita dos pais desde o 1.0 dia de hospitalização, inclusive no período crítico de permanência em isolamento rigoroso, pôde-se notar que a presença diária desses era para ele motivo de conforto, segurança, uma cha- ma viva que alimentava dia a dia sua forte vontade de viver; fato por todos percebido e comentado. Quando se aproximava a hora da chegada dos pais, seus olhos, antes céreos, parados, tornavam-se brilhantes, inquiridores, buscando alhures. Nos lábios, apesar dos gemidos que já se tornavam esparsos, um pálido e sofrido sorriso de criança se esboçava. No seio familiar não se notava pieguice afetiva ou fraqueza. Os pais, simples e humildes, mas emocionalmente equilibrados. A mãe, com espírito genuinamente maternal, dava-lhe um sentimento básico de confiança naqueles que o cercavam. O pai tranquiilo, positivo, amoroso, partilhava com a mãe as diversas responsabilidades que os envolviam na assistência ao filho enfermo, mantendo atenção para com todos e em momento algum deixava transparecer por este ou aquele membro da equipe.

\section{RESUMO}

Tratava-se de um adolescente de cor parda, que deu ontrada na emergência da UISS, sendo feito diagnóstico de estafilocococia, evoluindo com septicemia, abcessos múltiplos, endocardite, osteomielite, dando-se ênfase à relação harmoniosa entre paciente, familiares e equipe Assistencial.

\section{RECOMENDAÇÕES}

1) Considerando as normas administrativas e rotinas hospitalares muito rígidas e que muitas vezes interferem no tratamento e recuperação do paciente, recomenda-se:

- que haja maior flexibilidade e participação da equipe Assistencial na elaboração dessas normas e rotinas, revertendo-se o resultado no bem-estar dos pacientes em geral. 
SILVA, M.R.P. e Colaboradores - Evolução clínica de um paciente septicêmico. A interferência da equipe de saúde e da familia no aspecto emocional do paciente. Rev. Bras. Enf.: DF, 33 : 418-423, 1980.

2) Considerando o envolvimento da equipe Assistencial durante todo o período de internação do paciente, acompanhando passo a passo a sua evolução e dela participando ativamente, recomenda-se:

- que a equipe Assistencial envolvase com todos os pacientes, dandolhes a atenção adequada, sem levar em conta a patologia mais interessante ou menos interessante, mas apenas o ser na sua individualidade.

3) Considerando que a diretriz da assistência é de importância fundamental na determinação dos resultados para o paciente, recomendase:

- que os serviços de Enfermagem, apoiados pela administração das Instituições de Saúde a que servem, promovam e desenvolvam a educação continuada do seu pessoal, a fim de proporcionar-lhe a maturidade emocional e profissional indispensável ao encaminhamento do referido resultado.

\section{ENTREVISTA COM O PACIENTE}

01 - De que maneira ajuda a sua família e desde quando trabalha?

R. - Desde os 7 anos de idade, sou engraxate.

02 - Qual a maior preocupação na época em que esteve internado?

R. - Medo de não voltar para minha casa.

03 - Quando você tomou conhecimento de que era paciente e que ficaria internado por tempo indeterminado, o que pensou?

R. - Pensei que ia ficar muito tempo no hospital, tive medo, mas nun- ca pensei em morrer, porque tenho fé em Deus e em vocês.

04 - Quando seu pai visitou-o pela primeira vez, o que você sentiu?

R. - Fiquei emocionado, não esperava a visita dele naquele dia. Pedi para o meu pai me benzer e fazer o sinal da cruz na minha cabeça e fazer promessa para eu ficar bom.

05 - Em algum momento, a equipe médica lhe causou alguma insegurança?

R. - Sim, tive dúvida, porque tinha muito médico ao meu redor $e$ ao mesmo tempo.

06 - O que marcou, a seu ver, a presença da equipe de Enfermagem?

R. - Gostei de todas, porque elas me tratavam com cuidado e conversavam comigo.

07 - O que é mais importante na sua vida?

R. - E a minha saúde.

08 - O que sentia quando seu médico residente estava presente?

R. - Sentia bem, não tinha medo, porque confiava nele.

09 - As visitas de sua mãe foram importantes?

R. - Sim, porque não me sentia só.

10 - O que acha que seus irmãos pensam de você?

R. - Sinto que meus irmãos gostam de mim.

11 - As demais visitas foram importantes para você, por quê?

R. - Porque eu queria ver meus amigos, sentia saudades deles.

12 - O que foi mais significativo e lhe deu forças para recuperar-se? 
SILVA, M.R.P. e Colaboradores - Evolução clínica de um paciente septicêmico. A interferência da equipe de saúde e da família no aspecto emocional do paciente. Rov. Bras. Enf.: DF, 33 : 418-423, 1980.

R. - A fé e a minha família perto de mim.

13 - Quando desceu da cama pela primeira vez, o que achou?

R. - Senti mais confiante e achei que ia ficar bom.

14 - Quando saiu do isolamento pela primeira vez, o que achou?

R. - Senti-me mais livre.

15 - Depois da doença, você modificou seu comportamento e relacionamento com os familiares?

R. - Mudei para melhor, reciprocamente.

16 - Qual o seu objetivo para o futuro?

R. - Ser advogado.

17 - Qual o seu passatempo?

R. - Gosto de jogar bola, ver filme de televisão, jogar baralho, só não gosto de circo.

18 - Em algum tempo, você ficou preocupado em não poder mais se divertir, ou voltar às atividades diárias?

R. - Sim, tive medo de ficar sem andar, e não poder fazer mais o que fazia antes.

19 - O que sentiu quando soube que estava de alta?

R. - Uma alegria muito grande, pois sabia que ia para casa.

20 - Ao chegar em casa, qual foi sua reação?

R. - Emocionei-me.

Nesse ponto, o paciente não teve mais condições de diálogo, a não ser dizer que se sentiu feliz, mas também sentiu falta do pessoal que o cercava.

\section{BIBLIOGRAFIA}

BEESON, McDermott - Tratado de Medicina Interna, 14. a edição, Volume Interamericana, págs. 420 a 424.

FAVRETTO, Arcidio - O Doente: Razão de ser do Hospital, 3. ${ }^{a}$ edição, pág. 59, 1977.

MASON, Mildred A. - Enfermagem MédicoCirúrgica, 3. ${ }^{\text {a }}$ edição. Editora Interamericana Ltda., pág. 4, 1976.
PERES TRELLO, Danilo - A Medicina da Pessoa, 1. ${ }^{\text {a }}$ edição. Ed. RJ. Ateneu, págs. 95 a 163, 1974.

VERONESI, Ricardo - Doenças Infecciosas e Parasitárias, 6. ${ }^{a}$ edição. Ed. Guanabara, Koogan, pág. 334. 